\title{
The efficacy of caffeine-potentiated chemotherapy in clear cell sarcoma
}

\author{
Robin L. Jones • Anastasia Constantinidou
}

Received: 16 December 2011/ Accepted: 5 January 2012/Published online: 7 February 2012

(C) Japan Society of Clinical Oncology 2012

Keywords Clear cell sarcoma · Chemotherapy · Caffeine-potentiated chemotherapy

To the editor,

We read with great interest the study by Karita and colleagues [1] on the efficacy of caffeine-potentiated chemotherapy in clear cell sarcoma. The authors are to be congratulated for publishing promising data on a rare disease. However, several points should be clarified for the benefit of readers. The response rate to chemotherapy cannot be assessed in the adjuvant setting. The quoted study by Kuiper et al. [2] did not report a response rate of $25 \%$ ( 1 out of 4 patients), as these investigators treated 3 patients with adjuvant chemotherapy. Furthermore, the authors state that chemotherapy has "little impact" on survival with overall survival rates of $55-68 \%$. No comment can be made on the effect on survival of adjuvant chemotherapy from these retrospective studies and case reports in such a rare disease.

The authors state that "it is generally thought that chemotherapy results in poor response and survival" in clear cell sarcoma, but do not reference this statement. In a series of twenty-four patients with locally advanced and metastatic clear cell sarcoma, the response rate to chemotherapy was $4 \%$, the median progression-free survival was

R. L. Jones ( $₫)$

University of Washington/Fred Hutchinson Cancer Research

Center, 825 Eastlake Avenue East, Seattle, WA, USA

e-mail: rjones@seattlecca.org

A. Constantinidou

Royal Marsden Hospital, London, UK

e-mail: Anastasia.constantinidou@icr.ac.uk
11 weeks (95\% CI 3-20 weeks), and the median overall survival was 39 weeks (95\% CI 34-45 weeks) [3]. Although response rate is not a perfect end point, the criteria used should be quoted correctly. The authors state that RECIST defines a partial response as more than 50\% tumor shrinkage [1]; in fact, a partial response is defined as a shrinkage of $>30 \%$, progressive disease is an increase of $>20 \%$, and stable disease is a decrease of $\leq 30 \%$ or an increase of $\leq 20 \%$.

The authors have performed a promising study, and their results should be confirmed in larger prospective trials. Improvements in the management of rare diseases such as clear cell sarcoma can only come through international collaboration.

Conflict of interest Dr Robin L. Jones and Dr Anastasia Constantinidou declare no conflict of interest for their submission: "The efficacy of caffeine-potentiated chemotherapy in clear cell sarcoma."

\section{References}

1. Karita M, Tsuchiya H, Yamamoto N et al (2011) Caffeinepotentiated chemotherapy for clear cell sarcoma: a report of five cases. Int J Clin Oncol. doi:10.1007/s10147-011-0337-9

2. Kuiper DR, Hoekstra HJ, Veth RP et al (2003) The management of clear cell sarcoma. Eur J Surg Oncol 29(7):568-570

3. Jones RL, Constantinidou A, Thway K et al (2011) Chemotherapy in clear cell sarcoma. Med Oncol 28:859-863 